Atmos. Chem. Phys., 10, 6169-6178, 2010

www.atmos-chem-phys.net/10/6169/2010/

doi:10.5194/acp-10-6169-2010

(C) Author(s) 2010. CC Attribution 3.0 License.

\title{
Isoprene nitrates: preparation, separation, identification, yields, and atmospheric chemistry
}

\author{
A. L. Lockwood ${ }^{1,}$, P. B. Shepson ${ }^{1,2}$, M. N. Fiddler ${ }^{1}$, and M. Alaghmand ${ }^{1}$ \\ ${ }^{1}$ Department of Chemistry, Purdue University, 560 Oval Dr. West Lafayette, IN 47907, USA \\ ${ }^{2}$ Department of Earth and Atmospheric Sciences, Purdue University, 560 Oval Dr. West Lafayette, IN 47907, USA \\ * currently at: Clarion University of PA, Dept. of Chemistry and Biochemistry, 840 Wood St., Clarion, PA 16214, USA
}

Received: 8 April 2010 - Published in Atmos. Chem. Phys. Discuss.: 22 April 2010

Revised: 24 June 2010 - Accepted: 25 June 2010 - Published: 8 July 2010

\begin{abstract}
Isoprene is an important atmospheric volatile organic compound involved in ozone production and $\mathrm{NO}_{\mathrm{x}}$ $\left(\mathrm{NO}+\mathrm{NO}_{2}\right)$ sequestration and transport. Isoprene reaction with $\mathrm{OH}$ in the presence of $\mathrm{NO}$ can form either isoprene hydroxy nitrates ("isoprene nitrates") or convert $\mathrm{NO}$ to $\mathrm{NO}_{2}$ which can photolyze to form ozone. While it has been shown that isoprene nitrate production can represent an important sink for $\mathrm{NO}_{\mathrm{x}}$ in forest impacted environments, there is little experimental knowledge of the relative importance of the individual isoprene nitrate isomers, each of which has a different fate and reactivity. In this work, we have identified the 8 individual isomers and determined their total and individual production yields. The overall yield of isoprene nitrates at atmospheric pressure and $295 \mathrm{~K}$ was found to be $0.070(+0.025 /-0.015)$. Three isomers, representing nitrates resulting from $\mathrm{OH}$ addition to a terminal carbon, represent $90 \%$ of the total IN yield. We also determined the ozone rate constants for three of the isomers, and have calculated their atmospheric lifetimes, which range from $\sim 1-2 \mathrm{~h}$, making their oxidation products likely more important as atmospheric organic nitrates and sinks for nitrogen.
\end{abstract}

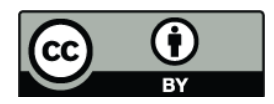

Correspondence to: P. B. Shepson (pshepson@purdue.edu)

\section{Introduction}

Isoprene (2-methyl-1,3-butadiene) is the dominant biogenic volatile organic compound emitted into the atmosphere at $500-750 \mathrm{Tg} \mathrm{yr}^{-1}$ (Guenther et al., 2006). Isoprene is emitted by plants and readily reacts with $\mathrm{OH}$ radicals, ozone, and $\mathrm{NO}_{3}$ in the atmosphere (Tuazon and Atkinson, 1990; Chuong and Stevens, 2002; Guenther et al., 2006). Reaction with $\mathrm{OH}$ is the dominant pathway for the removal of isoprene during the day $\left(k=1.0 \times 10^{-10} \mathrm{~cm}^{3}\right.$ molecule $\left.{ }^{-1} \mathrm{~s}^{-1}\right)$ (Atkinson et al., 2006). Reactions (R1-R3) show a simple mechanism for the addition of $\mathrm{OH}$ and $\mathrm{O}_{2}$ to one of the four double-bonded carbons (Reaction R1) to produce either the alkoxy radical and

$$
\begin{aligned}
& \mathrm{C}_{5} \mathrm{H}_{8}+\mathrm{OH}\left(+\mathrm{O}_{2}\right) \rightarrow \cdot \mathrm{O}-\mathrm{O}-\mathrm{C}_{5} \mathrm{H}_{8}-\mathrm{OH} \\
& \cdot \mathrm{O}-\mathrm{O}-\mathrm{C}_{5} \mathrm{H}_{8}-\mathrm{OH}+\mathrm{NO} \rightarrow \cdot \mathrm{O}-\mathrm{C}_{5} \mathrm{H}_{8}-\mathrm{OH}+\mathrm{NO}_{2} \\
& \mathrm{O}-\mathrm{O}-\mathrm{C}_{5} \mathrm{H}_{8}-\mathrm{OH}+\mathrm{NO} \rightarrow \mathrm{O}_{2} \mathrm{~N}-\mathrm{O}-\mathrm{C}_{5} \mathrm{H}_{8}-\mathrm{OH}
\end{aligned}
$$

$\mathrm{NO}_{2}$ (Reaction R2), or a hydroxy nitrate ("isoprene nitrate") (Reaction R3). The $\mathrm{NO}_{2}$ formed in Reaction (R2) can photolyze to produce ozone (Reactions R4 and R5). Competing with Reaction (R2)

$$
\begin{aligned}
& \mathrm{NO}_{2}+\mathrm{h} v \rightarrow \mathrm{NO}+\mathrm{O}\left({ }^{3} \mathrm{P}\right) \\
& \mathrm{O}\left({ }^{3} \mathrm{P}\right)+\mathrm{O}_{2} \rightarrow \mathrm{O}_{3}
\end{aligned}
$$

and 3 is reaction of the hydroxyperoxy radicals with $\mathrm{HO}_{2}$, to produce organic hydroperoxides, and ultimately, dihydroxyepoxides (Paulot et al., 2009a). However, in the northern

Published by Copernicus Publications on behalf of the European Geosciences Union. 
hemisphere continental environments, the majority of peroxy radicals will react with NO (Barket et al., 2004; Paulot et al., 2009a), and thus the nitrate formation pathways and subsequent chemistry are very important.

Isoprene nitrate (IN) production, according to global modeling studies, has a significant impact on ozone production (Wu et al., 2007). INs act as a sink for $\mathrm{NO}_{\mathrm{x}}\left(\mathrm{NO}+\mathrm{NO}_{2}\right)$, removing both the peroxy radicals and $\mathrm{NO}_{\mathrm{x}}$ that would otherwise produce $\mathrm{O}_{3}$ (Horowitz et al., 2007). The yield $\left(k_{3} /\left(k_{2}+k_{3}\right)\right)$ for the IN produced in Reaction (R3) has a significant impact on $\mathrm{O}_{3}$ production efficiency, as it impacts the magnitude of the chain length, being an important termination step (Horowitz et al., 2007; Wu et al., 2007).

For this paper, we apply a short-hand nomenclature for the individual IN isomers, according to which carbon has the $\mathrm{OH}$ and $\mathrm{ONO}_{2}$ groups attached. The first number is the carbon to which the $\mathrm{OH}$ is attached and the second number is the carbon to which the $\mathrm{ONO}_{2}$ is attached. For example, we refer to $\mathrm{HOCH}_{2} \mathrm{C}\left(\mathrm{CH}_{3}\right)\left(\mathrm{ONO}_{2}\right) \mathrm{CH}=\mathrm{CH}_{2}$ as the $(1,2)$-IN. Eight isoprene nitrate isomers (INs), including the Z- and E- isomers of the $(1,4)$ - and the $(4,1)$-INs, formed from Reactions (R1) and (R3), are shown in Fig. 1 (Chen et al., 1998). These isoprene nitrates are very reactive because they are still olefinic. Their atmospheric oxidation products, which are longer lived than the parent INs because they are saturated, are likely more important than the original nitrate with regard to transport and deposition (Giacopelli et al., 2005; Horowitz et al., 2007; Paulot et al., 2009b). For example, a likely product of $\mathrm{O}_{3}$ oxidation of the (1,2)-IN is $\mathrm{HOCH}_{2} \mathrm{C}\left(\mathrm{CH}_{3}\right)\left(\mathrm{ONO}_{2}\right) \mathrm{COOH}$, which would likely have a large deposition velocity.

The reported yields for total IN production yield range from $4.4 \%$ to $15 \%$ (Tuazon and Atkinson, 1990; Chen et al., 1998; Chuong and Stevens, 2002; Sprengnether et al., 2002; Patchen et al., 2007). Tuazon and Atkinson (1990) and Sprengnether et al. (2002) determined their reported yields of $8-13 \%$ and $12 \%$, respectively, using FT-IR. Chen et al. (1998) utilized a nitrate selective detector to measure the INs using chamber experiments and gas chromatography. They determined a yield of $4.4( \pm 0.8) \%$. However, they were not able to differentiate between the individual isomers. Chuong and Stevens (2002) used turbulent flow laser induced fluorescence to determine a yield of $15( \pm 10) \%$. The yield was measured indirectly and has a large uncertainty due to the sensitivity of the simulation approach used for the determination. The most recent reported yields for IN production are 7\% (Patchen et al., 2007) and 11.7\% (Paulot et al., 2009b). The work of Patchen et al. (2007) was for 100 Torr, and thus the yield at atmospheric pressure may be greater than the 7\% reported (Arey et al., 2001). However, individual isomer yields have not been determined because up to this point, no standard has been available.

It has been discussed by Giacopelli et al. (2005) that the lifetimes of the individual INs are likely quite different, and thus the ultimate distribution of isomers in ambient air will
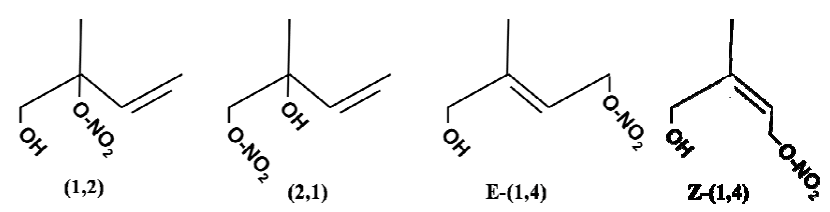

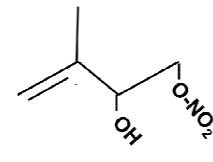

$(3,4)$
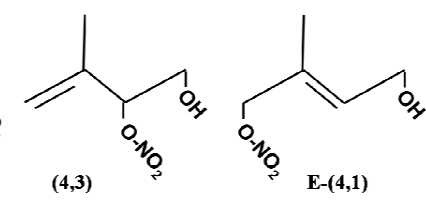

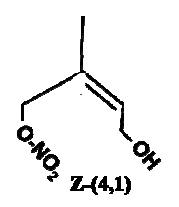

Fig. 1. Isoprene nitrate isomers.

reflect both the product yields, and the relative IN lifetimes. Furthermore, it is quite important to note that some isomers may react with $\mathrm{OH}$ or $\mathrm{O}_{3}$ to release $\mathrm{NO}_{2}$ (Paulot et al., 2009b), which in turn, significantly affects their impact on ambient $\mathrm{NO}_{2}$ and $\mathrm{O}_{3}$ concentrations (Horowitz et al., 2007). Thus the determination of the individual isomer product yields is of critical importance.

In this work, we have synthesized three of the isoprene nitrate isomers. They were separated and identified, and their ozone rate constants were determined. Unlike in the field, where only 2 INs have been detected, thought to be the $(1,2)$ IN and (4,3)-IN (Grossenbacher et al., 2004; Giacopelli et al., 2005), all 8 were detected in photochemical reaction chamber experiments. Because of this, the total yield and individual yields for each of the 8 INs were determined and their atmospheric lifetimes with regard to $\mathrm{OH}$ and ozone were calculated.

\section{Experimental}

\subsection{Synthesis}

Three isoprene nitrates, the $(1,2)-,(2,1)-$, and the $(1,4)-\mathrm{INs}$, were synthesized by adapting the Nichols et al. (1953) procedure. Isoprene monoxide (IM, 2-methyl-2-vinyl oxirane, Aldrich) in anhydrous cyclohexane $(99.5 \%$, Aldrich) at a concentration of $0.03 \mathrm{M}$ was cooled to $\sim 15^{\circ} \mathrm{C}$ in a 3-neck round bottom flask in an ice bath. The flask was covered with aluminum foil to reduce light exposure and purged with $\mathrm{N}_{2}$ (grade 5.0, Praxair) as it cooled to minimize water condensation on the inside of the flask. Fuming nitric acid (Aldrich) was added to the flask in a molar ratio of 1:1.5 $\left(\mathrm{HNO}_{3}: \mathrm{IM}\right.$ solution) and then stirred with a stir bar for $30 \mathrm{~min}$. The solution was removed from the flask, stored in a glass amber bottle, and placed in the freezer. Figure 2 shows the synthesis chemistry. 


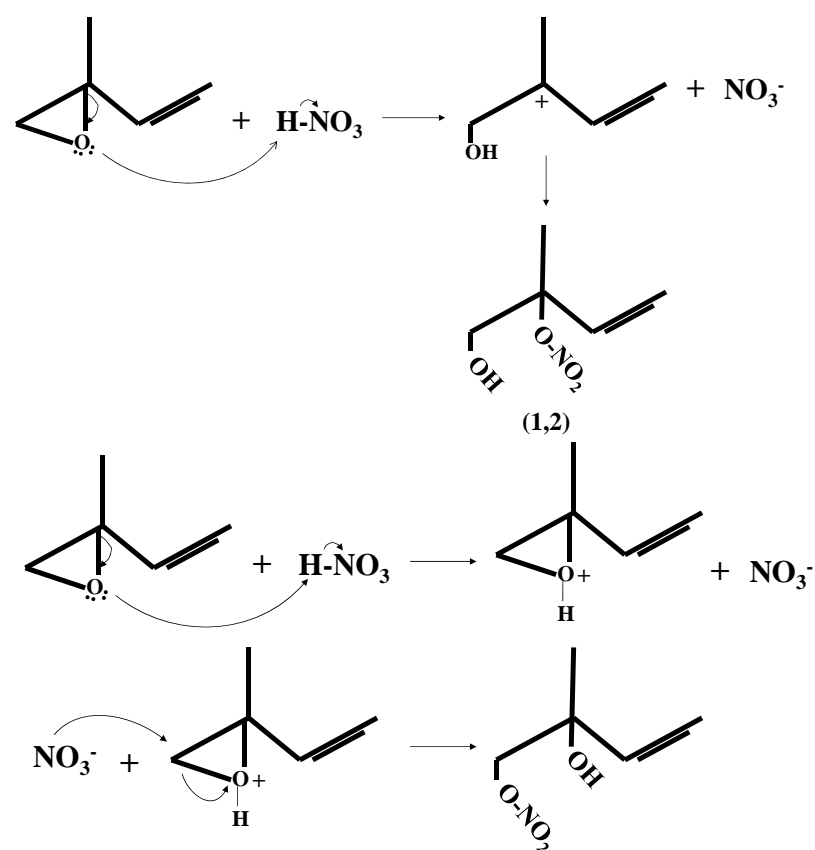

$(2,1)$

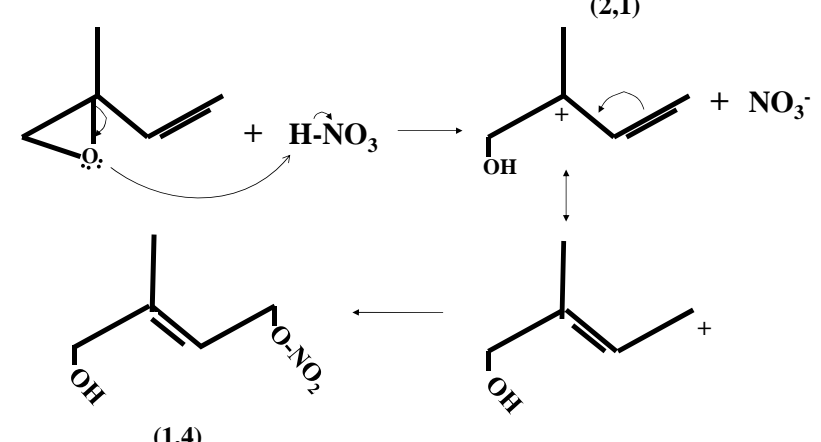

$(1,4)$

Fig. 2. Isoprene nitrate synthesis chemistry.

\subsection{HPLC separation}

The synthesized isoprene nitrates were separated and purified using a Waters 501 HPLC in preparative mode, normal phase, with a Zorbax Eclipse XDB-CN cyano column $(4.6 \times 150 \mathrm{~mm}, 3.5 \mu \mathrm{m}$, Agilent), and detected with a Waters 990 photodiode array detector $(\lambda=220 \mathrm{~nm})$. The mobile phase was HPLC grade hexane (Aldrich) at $1 \mathrm{~mL} \mathrm{~min}^{-1}$ that had been dried using anhydrous $\mathrm{MgSO}_{4}$ (Aldrich). For preparative separation, we used a $100 \mu \mathrm{L}$ stainless steel sample loop. The INs eluted according to increasing polarity and separated in the first $8 \mathrm{~min}$ (Fig. 3). Each isoprene nitrate was collected in a separate amber bottle. To further purify the isomers, each isomer solution was re-injected into the HPLC using a $20 \mu \mathrm{L}$ sample loop and re-collected. Each individual IN solution was concentrated using $\mathrm{N}_{2}$ (grade 5.0, Praxair) to evaporate most of the hexane and then stored in a freezer.

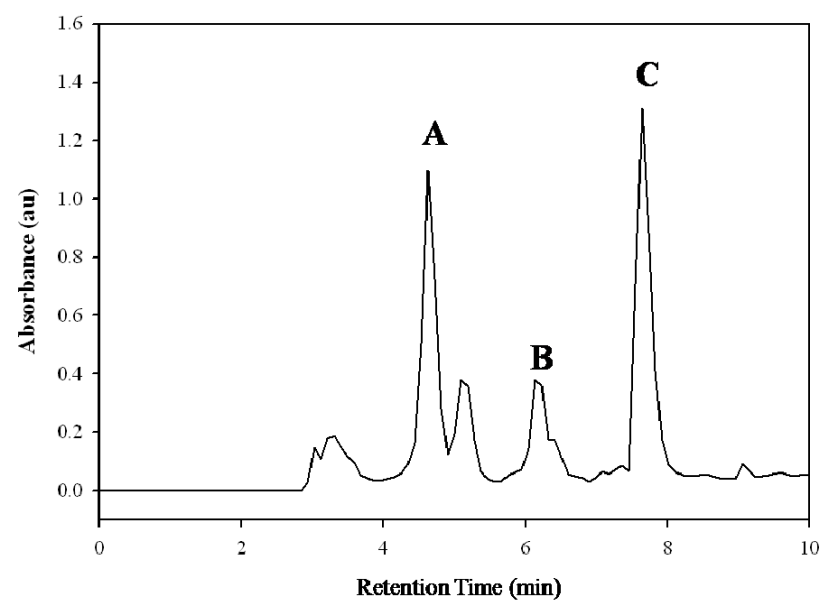

Fig. 3. HPLC chromatogram of the synthesized INs. The peaks labeled $\mathrm{A}-\mathrm{C}$ represent the individual IN isomers.

\subsection{Isoprene nitrate isomer identification}

A combination of the synthesis information, HPLC separation and elution order, gas chromatography-electron capture detector (GC-ECD), and GC-MS (EI, CI, and negative CI) data, Gaussian dipole moment calculations, and published mechanistic and theoretical information, was used to identify the synthesized isoprene nitrates. The GC-ECD coupled an HP 5890 Series II GC using a RTX-1701 column (30 m, $0.53 \mathrm{~mm}$ i.d., $3.0 \mu \mathrm{m}$ film thickness, Restek) with a pulseddischarge electron capture detector $\left(\mathrm{ECD}, 220^{\circ} \mathrm{C}\right.$, Valco). A $10 \mathrm{~mL}$ stainless steel sample loop and liquid nitrogen column cryo-focusing were used to concentrate the INs at the head of the GC column to obtain a detection limit of $\sim 3$ ppt. The GC temperature program was as follows: $-20^{\circ} \mathrm{C}$ for $2 \mathrm{~min}$, $20^{\circ} \mathrm{C} \mathrm{min}^{-1}$ to $120^{\circ} \mathrm{C}, 2^{\circ} \mathrm{C} \mathrm{min}^{-1}$ to $140^{\circ} \mathrm{C}$, held for $9 \mathrm{~min}$, $8^{\circ} \mathrm{C} \mathrm{min}{ }^{-1}$ to $220^{\circ} \mathrm{C}$, then held for $5 \mathrm{~min}$. The sample inlet and the $10 \mathrm{~mL}$ sample loop were heated to $70^{\circ} \mathrm{C}$ and $100^{\circ} \mathrm{C}$, respectively, to avoid surface losses. These temperatures are much too low for any thermal degradation of the nitrates. One sample could be injected every $49 \mathrm{~min}$. The GC-ECD inlet, sample loop, and column were conditioned (Muthuramu et al., 1993) with a large gas phase concentration of the synthesized isoprene nitrates to alleviate adsorptive losses of the INs during experiments. We found that blanks following these samples were free of INs, indicating that the uptake of the INs from "conditioning" samples was irreversible.

The ECD detects the isoprene nitrates with very good sensitivity. However, it responds slightly differently to different types of nitrates (Muthuramu et al., 1993) making calibrations difficult without standards, which up to now, have not been available for isoprene nitrates. A relative response experiment was conducted to determine the ECD detector response to an IN with respect to a readily available standard, isobutyl nitrate (IBN, Aldrich). A purified sample of the 
$(1,2)$-IN was used to calibrate the GC-ECD. To determine the absolute concentration of the $(1,2)$-IN in a gas phase standard, we used a custom-made total $\mathrm{RONO}_{2}$ detector, the Total Reactive Nitrogen Instrument (TRENI). This instrument detects organic nitrates using thermal decomposition to produce $\mathrm{NO}_{2}$, which is then photolytically converted to NO, followed by chemiluminescence-based detection of the NO. A heated quartz tube inlet $\left(400^{\circ} \mathrm{C}\right.$; Hao et al., 1994 ; Day et al., 2003) thermally decomposed the $\mathrm{IN}$ to $\mathrm{NO}_{2}$ (Reaction R6). The $\mathrm{NO}_{2}$ is then converted to $\mathrm{NO}$ using a photolytic converter via Reaction (R7). The NO is then reacted with

$$
\begin{aligned}
& \mathrm{RONO}_{2}+\Delta \rightarrow \mathrm{RO}+\mathrm{NO}_{2} \\
& \mathrm{NO}_{2}+h v \rightarrow \mathrm{NO}+\mathrm{O}\left({ }^{3} \mathrm{P}\right)
\end{aligned}
$$

ozone and the resulting photon emitted from the relaxation of the excited state $\mathrm{NO}_{2} *$ is detected by a photomultiplier tube.

Gas-phase samples of the purified $(1,2)$-IN were prepared in a PFA-Teflon bag, and the $\mathrm{RONO}_{2}$ concentration determined using TRENI. Samples of this secondary standard were then injected into the GC/ECD, to produce a calibration curve. The GC-ECD was calibrated at the same time with IBN over a concentration range of $0-20 \mathrm{ppb}$. Calibration curves for the (1,2)-IN and for IBN are shown in Fig. 4. The relative response, i.e. $S_{\mathrm{IN}} / S_{\mathrm{IBN}}$, was calculated by dividing the slope of the IN calibration curve by the slope of the IBN calibration curve to yield $S_{\mathrm{IN}} / S_{\mathrm{IBN}}=1.21( \pm 0.12,1 \mathrm{~s})$. This was the only IN for which a relative response factor was determined. This value can be compared to those values previously reported for other hydroxy nitrates by Muthuramu et al. (1993). They determined relative response factors (with respect to IBN) for several hydroxy nitrates that ranged from 0.92 for 1-nitroxy-2-hydroxy butane to 2.70 for 2-nitroxy-3hydroxy butane with an average value of $1.61( \pm 0.57)$. For this work, we will assume that the relative response (to IBN) for all of the INs is 1.21 , which falls within the uncertainty of the Muthuramu et al. (1993) average value for the $\alpha, \beta$ hydroxy nitrates.

A Finnigan GCQ-MS with a RTX-1701 column (30 m, $0.32 \mathrm{~mm}$ i.d., $1.0 \mu \mathrm{m}$ film thickness, Restek) utilized electron impact ionization, chemical ionization, and negative ion chemical ionization to determine the identity of the $(1,2)$ IN, which was synthesized. The temperature program was the same as for the GC-ECD with the exception that cryofocusing was not used, and the initial temperature was $40^{\circ} \mathrm{C}$ instead of $-20^{\circ} \mathrm{C}$.

The dipole moments of each of the $8 \mathrm{IN}$ isomers were calculated using Gaussian 03 at the B3PW91/6-31g(d) level, which uses Becke's three-parameter exchange and PerdewWang's correlation function (Frisch et al., 2003; Becke, 1993; Perdew et al., 1996). Structural minima were confirmed using frequency calculations, which yielded no imaginary frequencies. The calculated dipole moments for each IN isomer are listed in Table 1.

\subsection{Photochemical reaction chamber experiments}

A $5500 \mathrm{~L}$ Teflon photochemical reaction chamber was used to determine the yield of INs from the reaction of $\mathrm{OH}$ with isoprene in the presence of $\mathrm{NO}$, and is described elsewhere (Chen et al., 1998). The chamber was humidified prior to the yield experiments using a water bubbler to yield a final chamber relative humidity of $25-30 \%$, at $\sim 295 \mathrm{~K} . \mathrm{NO}_{2}$ was added to the chamber $\left(1.25 \times 10^{12}\right.$ to $2.5 \times 10^{12}$ molecules $\mathrm{cm}^{-3}$ ) at the start of the humidification to produce nitrous acid (HONO), which is formed on the walls of the chamber (Akimoto et al., 1987). Isoprene $\left(1.5 \times 10^{13}\right.$ to $4.5 \times 10^{13}$ molecules $\left.\mathrm{cm}^{-3}\right)$ and NO $\left(1 \times 10^{13}\right.$ to $3 \times 10^{13}$ molecules $\mathrm{cm}^{-3}$ ) were added to the chamber and allowed to mix. Once mixed, the UV lamps (maximum output occurs around $370 \mathrm{~nm}$ ) surrounding the chamber were turned on for 5-30 min intervals, initiating HONO photolysis, and then off during periods of analysis.

Isoprene concentrations were determined using a Varian 3300 GC with a PoraPak QS column (6 mmi.d. stainless steel packed column, Supelco Inc., Bellefonte, PA), separated isothermally at $175^{\circ} \mathrm{C}$, coupled with an FID detector $\left(250^{\circ} \mathrm{C}\right.$, GOW-MAC Instruments Co.). $\mathrm{NO}, \mathrm{NO}_{2}$, and $\mathrm{NO}_{\mathrm{x}}$ concentrations were determined using a Chemiluminescence $\mathrm{NO}-\mathrm{NO}_{2}-\mathrm{NO}_{\mathrm{x}}$ Analyzer (Model 42, Thermo Environmental Instruments Inc, Franklin, MA). A UV Photometric $\mathrm{O}_{3} \mathrm{An}-$ alyzer (Model 49, Thermo Environmental Instruments Inc, Franklin, MA) determined ozone concentrations throughout the experiment.

\subsection{Ozone rate constant experiments}

The rate constants for the reaction of several IN isomers with $\mathrm{O}_{3}$ were determined using the relative rate method (Atkinson et al., 1986). Ozone was generated using the ozone analyzer, and added to the chamber first, to a final concentration of 5-120 ppb. Approximately $8-12 \mathrm{~mL}$ (yielding $\sim 0.8-$ $1.8 \mathrm{ppb}$ of the three INs) of the synthesized IN solution was then rapidly injected into the chamber. Cyclohexane (anhydrous) from the IN solution (about $400 \mathrm{ppm}$ ) was used to scavenge $\mathrm{OH}$ radicals produced from the reaction of $\mathrm{O}_{3}$ with alkenes (Atkinson and Aschmann, 1993; Grosjean and Grosjean, 1998). Crotyl chloride (1-chloro-2-butene, Aldrich), the relative rate reference compound, was injected into the chamber to an initial concentration of $12-85 \mathrm{ppb}$. The compounds were allowed to mix for $10 \mathrm{~min}$. The peak heights for the 3 INs and for crotyl chloride (CC) were determined throughout the experiment using the GC-ECD.

$(1 / t) \cdot \ln \left\{\frac{\mathrm{IN}_{0}}{\mathrm{IN}_{t}}\right\}=(1 / t) \cdot \frac{k_{\mathrm{IN}}}{k_{\mathrm{CC}}} \ln \left\{\frac{\mathrm{CC}_{0}}{\mathrm{CC}_{t}}\right\}+k_{\mathrm{wl}}$ 


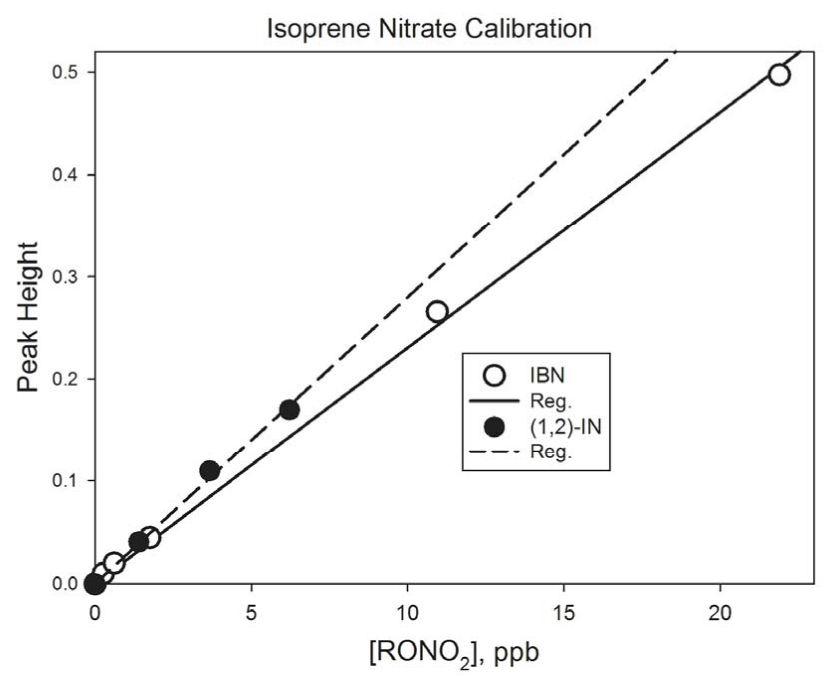

Fig. 4. Calibration curves for the (1,2)-IN and isobutyl nitrate.

Equation (1) shows the relative rate equation, including the impact of wall loss for the INs, where $k_{\mathrm{wl}}$ is the appropriate first order IN wall loss rate constant $\left(\mathrm{s}^{-1}\right)$. $\mathrm{IN}_{0}, \mathrm{CC}_{0}, \mathrm{IN}_{t}$, and $\mathrm{CC}_{t}$ are the

$\mathrm{IN}_{i}+\mathrm{O}_{3} \rightarrow$ loss

$\mathrm{CC}+\mathrm{O}_{3} \rightarrow$ loss

concentrations of each IN isomer and CC at time $t_{0}$ and $t$, respectively. The IN rate constants were determined by plotting $(1 / t) \cdot \ln \left([\mathrm{IN}]_{0} /[\mathrm{IN}]_{t}\right)$ vs. $(1 / t) \cdot \ln \left([\mathrm{CC}]_{0} /[\mathrm{CC}]_{t}\right)$ producing a slope equal to $k_{8} / k_{9}$ and an intercept equal to $k_{\mathrm{wl}}$. The CC reference ozone rate constant is 2.29 $( \pm 0.17) \times 10^{-17} \mathrm{~cm}^{3}$ molecules ${ }^{-1} \mathrm{~s}^{-1}$ (Johnson et al., 2000).

\section{Results and discussion}

\subsection{Isoprene nitrate identification}

The synthesized isoprene nitrates were separated using normal phase liquid chromatography. From the reaction of the isoprene monoxide with $\mathrm{HNO}_{3}$, it was possible to produce only the $(1,2)-I N$, the $(2,1)-I N$, and the $(1,4)-I N s$. The HPLC peaks labeled A-C in Fig. 4 were determined to be IN isomers. The absorption spectra for these three peaks, obtained from the HPLC diode array detector, are similar to each other and to a reference alkyl nitrate, IBN, indicating that peaks $\mathrm{A}-\mathrm{C}$ are organic nitrates. Given an expected elution order of increasing polarity, as expressed from the calculated dipole moments, peaks A, B, and C in Fig. 4 can be identified as the E-plus Z-(1,4)- (unresolved), the $(2,1)$-, and the $(1,2)-\mathrm{INs}$, respectively. The shoulder of Peak $A$ (not always resolved) could be one of the Z- or E-isomers of the $(1,4)$-IN. Peak $\mathrm{C}$ was completely separated from the rest of the synthesized

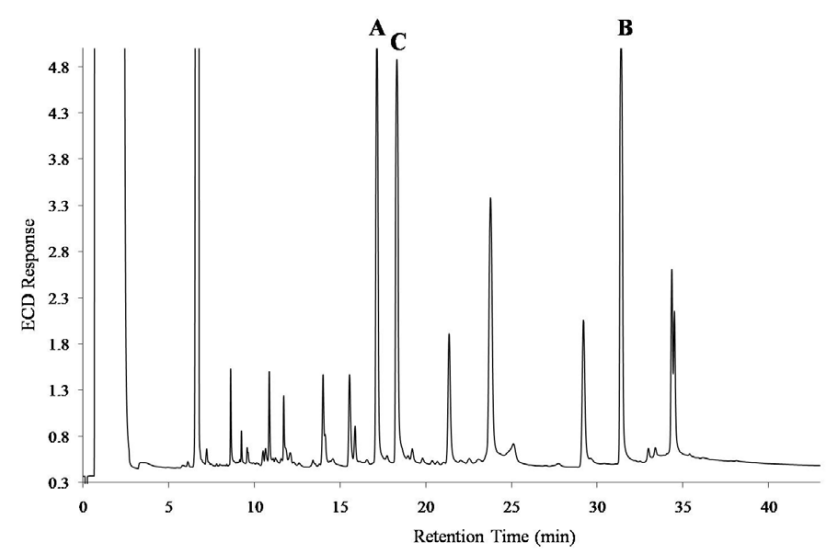

Fig. 5. GC-ECD chromatogram of the synthesized INs. The peaks labeled A-C correspond to the INs with the same label in Fig. 3.

INs by preparative HPLC. Peak A and B could not be completely isolated, based on analysis of the GC chromatograms for the HPLC-separated peaks, even though they were completely separated in the HPLC chromatogram (Fig. 3). Peak $\mathrm{C}$ is identified as the $(1,2)$-IN using the dipole moment calculations and the GC-MS analysis of the purified IN. Specifically, the $(2,1)$ - and the $(1,4)$-IN can have an $\alpha$-cleavage that would produce a $76 \mathrm{~m} / \mathrm{z}$ fragment $\left({ }^{+} \mathrm{CH}_{2}-\mathrm{ONO}_{2}\right)$, which is typical for primary nitrates (Luxenhofer et al., 1994; Schneider et al., 1998; Fischer et al., 2000). In contrast, the (1,2)-IN cannot produce that fragment, and the GC/MS spectrum for that peak did not yield a fragment at $m / z=76$. We therefore identified peak $\mathrm{C}$ in Fig. 4 as the $(1,2)-\mathrm{IN}$.

The GC peak assignments were conducted in part by comparing chromatograms from the total synthesized IN sample (Fig. 5) with that from an isoprene/ $\mathrm{NO}_{\mathrm{x}}$ irradiation chamber experiment (Fig. 6). The peaks in Fig. 5 labeled A-C correspond to the same peaks in the HPLC chromatogram in Fig. 3. The peaks labeled $1-8$ in the chamber experiment (Fig. 6) are identified as the INs. The peaks between 20 and $25 \mathrm{~min}$ are products of the direct $\mathrm{NO}_{2}$ reaction with isoprene, as discussed in Chen et al. (1998). The earlier peaks are light contaminants, perfluorocarbons from the bag, and secondary products from oxidation of species such as methyl vinyl ketone and methacrolein. All of the peaks that eluted before $10 \mathrm{~min}$ were present before the experiment began, eliminating them as possible INs. The IN peaks 5, 6 and 8 in Fig. 6 correspond to the HPLC peaks A, C, and B, respectively. Peak 6 is the $(1,2)$-IN because the peak matches up with the GC peak of the purified IN that was identified as the $(1,2)-$ IN by GC-MS analysis. The INs should elute from the GC column in approximate order of polarity from the semi-polar column phase, suggesting that the $(1,4)$-IN should elute before the (2,1)-IN (see Table 1). Therefore, peak 5 is assigned to one of the $(1,4)$-IN isomers, specifically the E- isomer. The E-(1,4)-IN has a smaller dipole moment (2.7903) than 
Table 1. Isoprene nitrate data. The peak numbers represent the peaks labeled in Fig. 5 and in the IN identification in the Results and Discussion section. $¥$ The $(4,1)$-IN isomers have 2 values for their lifetime. The lower value represents the lifetime using the average ozone rate constant $\left(1.67 \times 10^{-16} \mathrm{~cm}^{3}\right.$ molecule $\left.{ }^{-1} \mathrm{~s}^{-1}\right)$. The higher value represents the lifetime if we assume that the $(4,1)$-IN isomers have a similar ozone rate constant to the $(1,4)-\mathrm{IN}$.

\begin{tabular}{|c|c|c|c|c|c|c|c|c|c|c|c|}
\hline $\begin{array}{l}\text { Peak } \\
\text { Number }\end{array}$ & $\begin{array}{c}\text { Average } \\
\text { Retention } \\
\text { Time (min) }\end{array}$ & $\begin{array}{c}\text { IN } \\
\text { Identification }\end{array}$ & $\begin{array}{c}\text { Dipole } \\
\text { Moments }\end{array}$ & $\begin{array}{l}\text { Absolute } \\
\text { Yield }\end{array}$ & $\begin{array}{l}\text { Relative } \\
\text { Yield \% }\end{array}$ & $\begin{array}{l}\text { Ozone Rate Constant } \\
\begin{array}{c}\left(\mathrm{cm}^{3} \mathrm{molec}^{-1} \mathrm{~s}^{-1}\right) \\
\times 10^{-16}\end{array}\end{array}$ & $\begin{array}{c}\text { Calculated } \\
\text { Relative } \mathrm{RO}_{2} \\
\text { Yield }(\gamma)\end{array}$ & $\begin{array}{c}\text { Paulot et al. } \\
\gamma\end{array}$ & $\begin{array}{l}\text { Lei et al. }(2001) \\
\text { Calculated Relative } \\
\mathrm{RO}_{2} \text { Yield }(\gamma)\end{array}$ & $\begin{array}{c}\text { Atmospheric } \\
\text { Daytime } \\
\text { Lifetime }(\mathrm{h})^{\ddagger}\end{array}$ & $\begin{array}{l}\text { Calculated } \alpha_{i} \\
\text { using Paulot } \\
\text { et al. } \gamma_{i}\end{array}$ \\
\hline 1 & 12.47 & $\mathrm{Z}-4,1$ & 2.9804 & 0.0067 & 9.38 & - & 0.045 & 0.12 & \multirow{3}{*}{0.29} & 1.97 or 1.07 & 0.055 \\
\hline 2 & 13.1 & 4,3 & 3.9387 & 0.0356 & 49.9 & - & 0.61 & 0.23 & & 1.25 & 0.15 \\
\hline 3 & 14.21 & E-4,1 & 2.8789 & 0.0028 & 3.92 & - & 0.019 & 0.021 & & 1.97 or 1.07 & 0.13 \\
\hline 4 & 15.00 & $Z-1,4$ & 3.2539 & 0.0015 & 2.10 & - & 0.010 & 0.13 & & 1.92 & 0.01 \\
\hline 5 & 17.18 & $E-1,4$ & 2.7903 & 0.0007 & 0.98 & $0.53( \pm 0.099)$ & 0.005 & 0.022 & & 1.92 & 0.03 \\
\hline 6 & 18.44 & 1,2 & 4.0902 & 0.0221 & 30.9 & $1.06( \pm 0.11)$ & 0.38 & 0.41 & 0.34 & 2.01 & 0.053 \\
\hline 7 & 30.43 & 3,4 & 3.5916 & 0.0003 & 0.42 & - & 0.052 & 0.05 & 0.05 & 1.22 & 0.0059 \\
\hline \multirow[t]{3}{*}{8} & 32.33 & 2,1 & 3.7383 & 0.0017 & 2.38 & $3.42( \pm 0.43)$ & 0.029 & 0.02 & 0.02 & 0.75 & 0.083 \\
\hline & & & & & & Z-plus E-(1,4) & 0.015 & 0.15 & 0.22 & & \\
\hline & & & & & & Z- plus E- $(4,1)$ & 0.063 & 0.14 & 0.08 & & \\
\hline
\end{tabular}

the Z-(1,4)-IN (3.2539) and would elute first from the HPLC column (peak A). Similarly, we assign peak 8 in Fig. 6 to the $(2,1)$-IN isomer.

Our peak identification assumes that the Z/E isomers are separable. To examine this, an alkene nitrate (1-nitroxy-1-propene) was synthesized using 1-bromo-1propene (Aldrich) and $\mathrm{AgNO}_{3}$ (Aldrich). The resulting Zand E-nitrates were injected onto the GC column to determine whether they could be separated, and if so, to what extent. The data show that the nitrates can be separated by the GC column, in this case, by $30 \mathrm{~s}$. By analogy, the Z-(1,4)-IN isomer should be separated from the E-(1,4)-IN already identified as peak 5 in Fig. 6 . Because peak 6 has already been identified as the $(1,2)$-IN, this leaves peak 4 as the only possible choice for the Z-(1,4)-IN isomer. Paulot et al. (2009b) discussed that the Z-isomer will be dominant over the E- isomer, which is consistent with the yield data discussed below. The $(3,4)$-IN isomer is assigned to peak 7 in Fig. 6, because two of the isomers, the $(2,1)$-IN and the $(3,4)$-IN should have very small yields (Giacopelli et al., 2005), and the $(2,1)$-IN is already identified, as discussed above. The $(2,1)$-IN and $(3,4)$-IN should have the lowest yields due to the instability of the primary carbon centered radical (Lei et al., 2001; Giacopelli et al., 2005). Because the (2,1)-IN has already been assigned to peak 8 , the $(3,4)$-IN is assigned to peak 7 .

The identification of the 3 remaining INs, the $(4,3)$-IN and the two $(4,1)$-IN isomers, is tentative. Based on the fact that the $(3,4)$ - plus the $(4,3)-\mathrm{RO}_{2}$ yield (discussed below) has to be at least as large as the methacrolein (MACR) yield of 27\% (Karl et al. 2006), since MACR is derived from those radicals, and since the $(4,3)-\mathrm{RO}_{2}$ yield is believed to be much larger than the $(3,4)-\mathrm{RO}_{2}$ yield (Lei et al., 2001; Giacopelli et al., 2005; Paulot et al., 2009b), the only IN that satisfies this latter requirement (along with peak 7) is peak 2 in Fig. 6. Peak 2 is thus assigned to the $(4,3)$-IN. The remaining 2 IN peaks, peaks 1 and 3 in Fig. 6, are assigned to the Z- and E-(4,1)-IN isomers, respectively. The two calculated dipole moments are not distinguishable, but the relative yields are consistent with the results from Paulot et al. (2009b) regarding the prevalence of the Z-isomer.

\subsection{Isoprene nitrate yields}

The total and individual isoprene nitrate yields were determined using GC-ECD and the photochemical reaction chamber. Isoprene and NO were added to the humidified chamber and the GC-ECD was used to determine the concentration of each isoprene nitrate over time during the irradiations. Using the ECD relative response factor $\left(1.21 \times S_{\text {isobutyl nitrate }}\right)$ for the INs, the individual and total concentrations of the 8 INs were calculated over the course of the yield experiment. Each of the individual IN concentrations were corrected for IN consumption by $\mathrm{OH}$, as described in Atkinson et al. (1982b), using the $k_{\mathrm{OH}}$ values reported in Giacopelli et al. (2005). The average correction factor for all the INs was $1.12( \pm 0.10)$. Given the small correction factor, uncertainties in the calculated rate constants should have a negligible effect on the yield results. For any individual nitrate, $\mathrm{IN}_{i}$, we have the following reactions accounting for individual isomeric IN production.

$$
\begin{aligned}
& \mathrm{OH}+\text { isop } \rightarrow \gamma_{i} \cdot \mathrm{RO}_{2, i} \\
& \mathrm{RO}_{2, i}+\mathrm{NO} \rightarrow \mathrm{RONO}_{2, i} \\
& \rightarrow \mathrm{RO}_{i}+\mathrm{NO}_{2}
\end{aligned}
$$

Here $\gamma_{i}$ is the fractional yield of the appropriate precursor peroxy radical. Since, assuming steady state in $\mathrm{RO}_{2, i}$, and where " $R$ " represents the reaction rate, $R_{10} \cdot \gamma_{i}=R_{11}$ and $R_{10}=k_{10}[\mathrm{OH}]$ [isop] and Eq. (2) then describes the isoprene decay rate. The rate of appearance of 


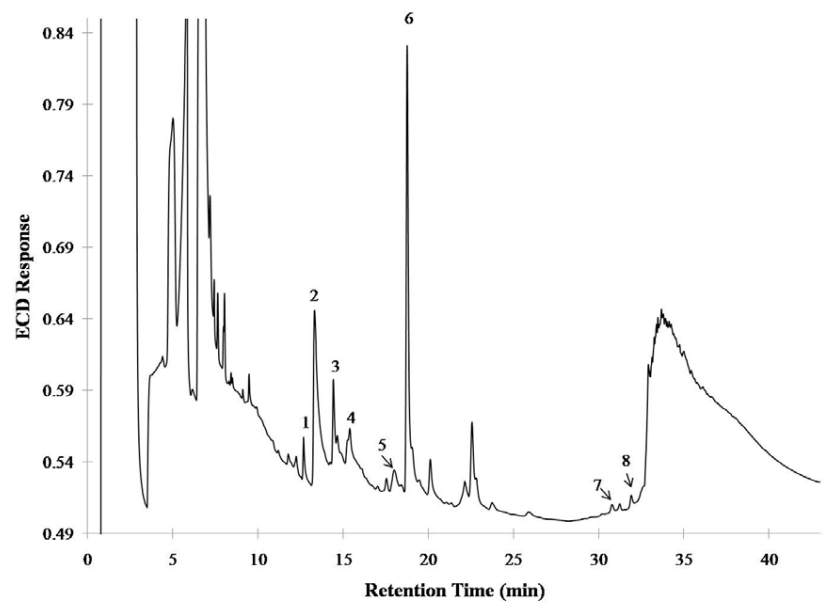

Fig. 6. GC-ECD chromatogram of an isoprene/ $\mathrm{NO}_{\mathrm{x}}$ yield experiment. The numbers correspond to the INs produced in the yield experiment.

$$
-d[\text { isop }] / \mathrm{d} t=R_{11} / \gamma_{i}=k_{11}\left[\mathrm{RO}_{2, \mathrm{i}}\right][\mathrm{NO}] / \gamma_{i}
$$

$d\left[\mathrm{RONO}_{2, i}\right] / \mathrm{d} t=R_{11 a}=k_{11 a}\left[\mathrm{RO}_{2, \mathrm{i}}\right][\mathrm{NO}]$

$\mathrm{RONO}_{2, i}$ is described by Eq. (3), and thus if we plot $\Delta\left[\mathrm{RONO}_{2, i}\right]$ vs. $-\Delta\left[\right.$ isop] , the slope $=k_{11 a}\left[\mathrm{RO}_{2, i}\right][\mathrm{NO}] /$ $\left(k_{11}\left[\mathrm{RO}_{2, i}\right][\mathrm{NO}] / \gamma_{i}\right)=\gamma_{i} \cdot k_{11 a} / k_{11}$. Thus if $\gamma_{i}$ is known, the branching ratio, $\alpha_{i}=k_{11 a} / k_{11}$, for $\mathrm{RONO}_{2, i}$ formation, can be determined. If we plot $\Delta \Sigma\left[\mathrm{RONO}_{2, i}\right]$ vs. $-\Delta$ [isop], the slope is equal to the overall average ( $\gamma$-weighted) branching ratio, $R_{11 a} / \mathrm{R}_{11}$. The results for such a plot for all experiments are shown in Fig. 7, revealing a slope of $0.070 \pm 0.009(1 \mathrm{~s})$. The individual isomers' concentrations were plotted versus the loss of isoprene to obtain the individual yields, which are listed in Table 1 .

The relationship between size and structure of molecules and the branching ratios has been studied for simple molecules, but for multiply functionalized $\mathrm{RO}_{2}$ radicals, it is complex, and our understanding is quite limited (Espada and Shepson, 2005). We first note that three products, which we identify (see below) as the $(1,2)$-IN, the $(4,3)$-IN, and the Z-(4,1)-IN, represent $90 \%$ of the total IN yield. The Paulot et al. (2009b) study reports $61 \%$ of the total from these three isomers. Our reported overall yield is considerably greater than that (0.044) determined by Chen et al. (1998), using similar techniques. We attribute this to sampling losses, avoided here through "conditioning" of the sampling system with actual gas phase IN samples. However, given our previous experience of the potential for losses, and given the calibration uncertainty, we report a conservative asymmetric uncertainty for the total yield as $0.070(+0.025 /-0.015)$. The minimum in the uncertainty estimate derives from the propagated uncertainties, and the maximum represents the approximate upper limit of the data plotted in Fig. 7. Our total IN yield value agrees well with that of Patchen et al. (2007),

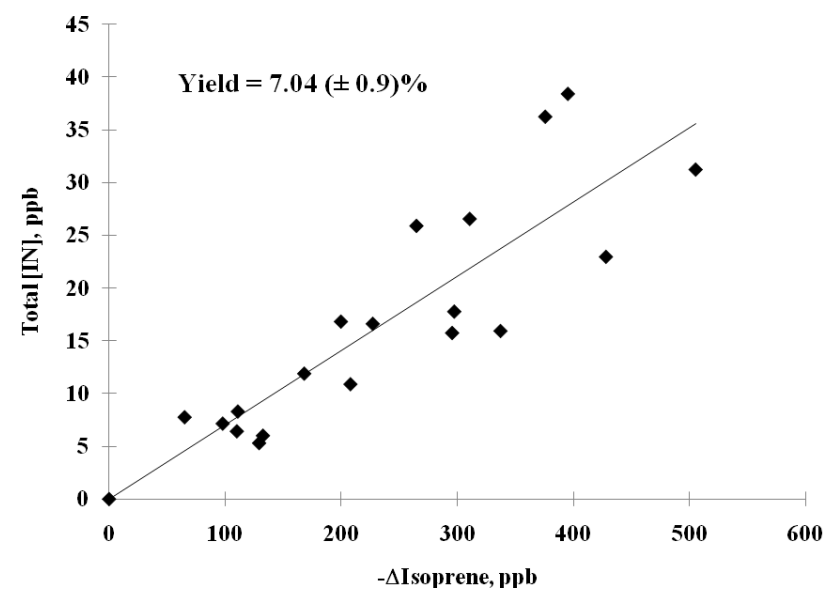

Fig. 7. Total isoprene nitrate yield. Total [IN] is plotted vs. the loss of isoprene over time. The data plotted are from multiple experiments. The uncertainty represents $1 \mathrm{~s}$.

who also obtained an overall yield of 0.07 , although at a total pressure of 100 Torr. This result then implies that 100 Torr is above the high pressure limiting value for the organic nitrate yield. Paulot et al. (2009b) derived an overall yield of 0.117 , using their combined measurement and modeling approach. Giacopelli et al. (2005) calculated an overall yield of 0.086 , based on structure-yield information from various literature information. Sprengnether et al. (2002) obtained the value 0.12 , while the original estimate from Tuazon and Atkinson (1990) was 0.08-0.13. It is clear that the range of values for this quantity is converging, with a current average reported yield of $\sim 0.09 \pm 0.02$. We note that while we observe that the $(1,2)$-IN is $\sim 31 \%$ of the total IN yield, Chen et al. (1998) observed that this peak was $45-65 \%$ of the total IN yield. In contrast, Paulot et al. (2009b) assume that the $(1,2)$-IN is $24 \%$ of the total IN yield, a bit smaller than our measured value.

In Table 1 we list the individual calculated yields, from the plots of $\Delta\left[\mathrm{RONO}_{2, i}\right]$ vs. $-\Delta$ [isop]. As discussed in Giacopelli et al. (2005), based on the work of Espada and Shepson (2005), we previously estimated that the branching ratio, $\alpha_{i}$, for $\alpha, \beta$-hydroxyperoxy radicals for isoprene is $\sim 0.058$, and for the $\delta$-hydroxyperoxy radicals, 0.15 . If we accept these values for $\alpha_{i}$, we can calculate values for the yield of each precursor $\mathrm{RO}_{2, i}, \gamma_{i}$; the results are shown in Table 1. We also show in Table 1 the values for $\gamma_{i}$ assumed by Paulot et al. (2009b). We can alternatively use the Paulot et al. (2009b) values for $\gamma_{i}$, and derive the corresponding values for $\alpha_{i}$; these are also shown in Table 1. The combination of these derived values are then useful for evaluation of the individual isomer identification. 


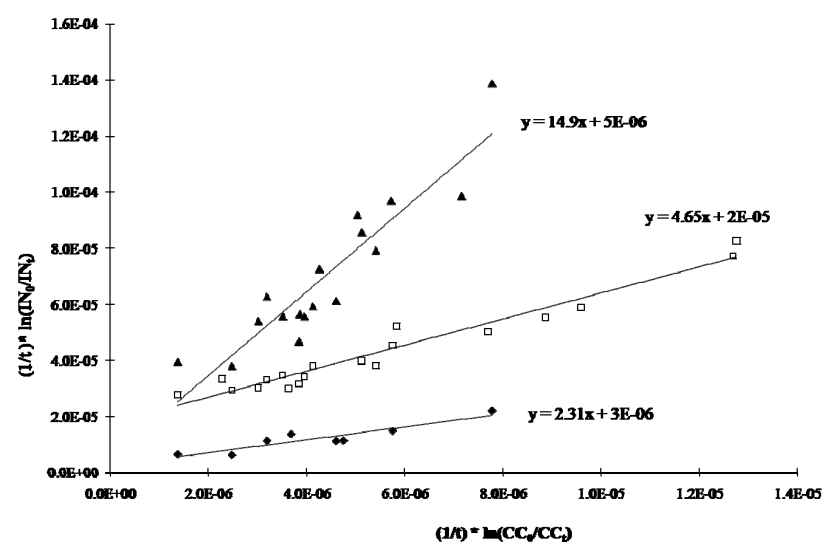

Fig. 8. Ozone rate constant data for three isoprene nitrate isomers. Triangles $=(2,1)-\mathrm{IN}$, squares $=(1,2)-\mathrm{IN}$, and diamonds $=\mathrm{E}-(1,4)-\mathrm{IN}$.

The principal uncertainty in isomer identification is in the identities for peaks 1 and 2 . We assigned these to the Z$(4,1)-\mathrm{IN}$ and the $(4,3)-\mathrm{IN}$, respectively. With these assignments, we calculate $\gamma_{i}$ values of 0.045 and 0.61 , respectively, for the corresponding $\mathrm{RO}_{2}$ precursor yields. While the latter value seems too large, if we reverse the assignments, the $\mathrm{RO}_{2}$ yields become 0.12 and 0.24 , respectively. In this latter case, the sum of the $(4,3)-\mathrm{RO}_{2}$ and $(3,4)-\mathrm{RO}_{2}$ yields would be 0.245 , which is less than the published yield for methacrolein (MACR) of 0.27 , which is not possible. Also, if we switch our assignment of peaks 1 and 2 to the (4,3)-IN and Z-(4,1)INs, respectively, we would calculate $\alpha_{i}$ values, using the Paulot et al. (2009) $\gamma_{i}$ values, of 0.029 and 0.30 , respectively, both of which seem unreasonable, compared to the values shown given our assignments, in Table 1. Thus, we believe that these are the only assignments that can be made that are consistent with the literature information. It should be noted that our calculated value for $\Sigma \gamma_{i}=115 \%$, a reasonable result of the propagation of the uncertainties in this analysis. We note that the calculated $\gamma_{i}$ values for the $(1,2)-\mathrm{RO}_{2}$ and $(2,1)$ $\mathrm{RO}_{2}$ radicals are 0.38 and 0.029 , for a total of 0.41 , in good agreement with the values (0.41 and 0.02) used by Paulot et al. (2009b), and consistent with the published MVK (which derives from these two radicals) yield of 0.41 (Karl et al., 2006). It thus appears from the calculated $\alpha_{i}$ values in Table 1 that there are factors influencing the range of individual $\alpha_{i}$ values for $\mathrm{RONO}_{2}$ production that are not yet understood.

\subsection{Isoprene nitrate lifetimes}

In Fig. 8 we present the combined data from 7 experiments for the $(1,2)$-IN and the $(2,1)$-IN and 6 experiments for the E-(1,4)-IN for the determination of the ozone rate constants. Using the rate constant for $\mathrm{O}_{3}$ reaction with crotyl chloride, the slopes yield values of 0.53, 1.06, and $3.4 \times 10^{-16} \mathrm{~cm}^{3}$ molecule $\mathrm{c}^{-1} \mathrm{~s}^{-1}$, which are very fast ozonolysis rate constants, corresponding to lifetimes against ozonolysis of 5, 2.6, and $0.8 \mathrm{~h}$, for the E-(1,4)-IN, $(1,2)-$ $\mathrm{IN}$, and (2,1)-IN, respectively, for $40 \mathrm{ppb}$ of $\mathrm{O}_{3}$. These rate constants are very large compared to the numbers assumed in Paulot et al. (2009b), and larger for the external olefinic INs, which is surprising. However, Paulot et al. (2009b) discuss that it appears that the nitrooxy group can increase the reactivity of double bonds to addition. We can estimate the individual IN isomer lifetimes with respect to ozone and $\mathrm{OH}$ using the ozone rate constants determined in this work and the $\mathrm{OH}$ rate constants calculated from the method of Kwok and Atkinson (1995). Because only 3 of the ozone rate constants were determined, an average rate of $1.7 \times 10^{-16} \mathrm{~cm}^{3}$ molecule $\mathrm{s}^{-1}$ was used for the remaining 5 INs. However, the $(4,1)$-IN isomers should have similar rate constants to those for the $(1,4)$ IN isomers, and thus for those isomers, we also calculated the lifetimes assuming they are the same as for the $(1,4)$-IN ozone rate constant. Assuming that $[\mathrm{OH}]=1 \times 10^{6}$, and using the values for $k_{\mathrm{OH}}$ presented in Giacopelli et al. (2005), and assuming $\left[\mathrm{O}_{3}\right]=1 \times 10^{12}$ molecules $\mathrm{cm}^{-3}$, the lifetimes for the isomers vary from $45 \mathrm{~min}$. for the $(2,1)-$ IN to two hours for the $(1,2)$-IN, as shown in Table 1 . The lifetimes are mostly impacted by ozonolysis. For example, for the $(1,2)-\mathrm{IN}$, the lifetime against $\mathrm{OH}$ loss is $8.1 \mathrm{~h}$. $\left(k=3.4 \times 10^{-11} \mathrm{~cm}^{3}\right.$ molecule $\left.{ }^{-1} \mathrm{~s}^{-1}\right)$, while for the $\mathrm{O}_{3}$ reaction, it is $2.6 \mathrm{~h}$. $\left(k=1.06 \times 10^{-16} \mathrm{~cm}^{3}\right.$ molecule $\left.{ }^{-1} \mathrm{~s}^{-1}\right)$. It is thus clear that the isoprene nitrates themselves will be relatively fleeting in the atmosphere, and will be quickly converted (if not lost by dry or wet deposition; Shepson et al., 1996) to either more complex multifunctional (highly water soluble and adsorptive) organic nitrates and/or dinitrates, or will recycle $\mathrm{NO}_{2}$ upon oxidation, as discussed by Giacopelli et al. (2005), Horowitz et al. (2007), and Paulot et al. (2009b). It is thus highly important that the fraction of $\mathrm{NO}_{\mathrm{x}}$ that is recycled upon reaction with $\mathrm{OH}$ and $\mathrm{O}_{3}$ be studied, at least for the three most important IN isomers.

In this work we were able to identify and quantify the individual isoprene nitrate isomers. We were able to synthesize, separate, and identify 3 of the 8 INs and determine their ozone rate constants. The total and individual yields for the INs were determined. The total IN yield is within the literature values and is similar to the most recently reported value of $7 \%$ (Patchen et al., 2007). The relatively short lifetime of the INs suggest that they act more like an intermediate product in the formation of less reactive dinitrates and carbonyl nitrates (Paulot et al., 2009b). They can either retain or release the $\mathrm{NO}_{\mathrm{x}}$, thus making the nature of the products of the INs reaction with $\mathrm{OH}$ and $\mathrm{O}_{3}$ important and worthy of further study. The methods described here for synthesis, purification and identification should help in enabling that study.

Acknowledgements. We are grateful to the National Science Foundation (Grant No. ATM0542701) for support of this work.

Edited by: J. Thornton 


\section{References}

Akimoto, H, Takagi, H., and Sakamaki, F.: Photoenhancement of the nitrous acid formation in the surface reaction of nitrogen dioxide and water vapor: extra radical source in smog chamber experiments. Int. J. Chem. Kinet., 19 539-551, 1987.

Arey, J., Aschmann, S. M., Kwok, E. S. C., et al.: Alkyl nitrate, hydroxylalkyl nitrate, and hydroxycarbonyl formation from the $\mathrm{NO}_{\mathrm{x}}$-air photooxidations of $\mathrm{C}_{5}-\mathrm{C}_{8}$ n-alkanes, J. Phys. Chem. A, 105, 1020-1027, 2001.

Atkinson, R., Aschmann, S. M., Carter, W. P. L., et al.: Kinetics of the gas-phase reactions of $\mathrm{OH}$ radicals with alkyl nitrates at 299 \pm 2 K, Int. J. Chem. Kinet., 14, 919-926, 1982a.

Atkinson, R., Aschmann, S. M., Carter, W. P. L., et al.: Alkyl nitrate formation from the $\mathrm{NOx}$-air photooxidations of $\mathrm{C}_{2}-\mathrm{C}_{9} \mathrm{n}$-alkanes, J. Phys. Chem., 86, 4563-4569, 1982 b.

Atkinson, R.: Kinetics and Mechanisms of The Gas-Phase Reactions of The Hydroxyl Radical With Organic-Compounds Under Atmospheric Conditions, Chem. Rev., 86, 69-201, 1986.

Atkinson, R. and Aschmann, S. M.: OH radical production from the gas-phase reactions of $\mathrm{O} 3$ with a series of alkenes under atmospheric conditions, Environ. Sci. Technol., 27, 1357-1363, 1993.

Atkinson, R., Baulch, D. L., Cox, R. A., Crowley, J. N., Hampson, R. F., Hynes, R. G., Jenkin, M. E., Rossi, M. J., Troe, J., and IUPAC Subcommittee: Evaluated kinetic and photochemical data for atmospheric chemistry: Volume II - gas phase reactions of organic species, Atmos. Chem. Phys., 6, 3625-4055, doi:10.5194/acp-6-3625-2006, 2006.

Barket, D. J., Hurst, J. M., Grossenbacher, J. W., Shepson, P. B., Brune, W., Thornberry, T., Carroll, M. A., Biesenthal, T., Bottenheim, J. W., and Olszyna, K. G.: A Study of the $\mathrm{NO}_{\mathrm{x}}$ Dependence of Isoprene Oxidation, J. Geophys. Res., 109, D11310, doi:10.1029/2003JD003965, 2004.

Becke, A. D., Density-Functional Thermochemistry .3. The Role Of Exact Exchange, J. Chem. Phys., 98, 5648-5652, 1993.

Biesenthal, T. A., Wu, Q., Shepson, P. B., et al.: A study of relationships between isoprene, its oxidation products, and ozone, in the lower Fraser Valley, BC, Atmos. Environ., 31(14) 2049-2058, 1997.

Chen, X. H., Hulbert, D., and Shepson, P. B.: Measurement of the organic nitrate yield from $\mathrm{OH}$ reaction with isoprene, J. Geophys. Res., 103, 25563-25568, 1998.

Christie, M. I. and Hetherington, P. M.: The photolysis of t-butyl, isopropyl and ethyl nitrites at $254 \mathrm{~nm}$, J. Photochem., 6, 285295, 1976.

Chuong, B. \& Stevens, P. S. Measurements of the kinetics of the OH-initiated oxidation of isoprene. J. Geophys. Res., 107, (2002).

Espada, C. and Shepson, P.: The production of organic nitrates from atmospheric oxidation of ethers and glycol ethers, Int. J. Chem. Kinet., 37, 686-699, 2005.

Fisher, R. G., Kastler, J., Ballschmiter, K., et al.: Levels and pattern of alkyl nitrates, multifunctional alkyl nitrates, and halocarbons in the air over the Atlantic Ocean, J. Geophys. Res., 105, 1447314494, 2000.

Frisch, M. J., Trucks, G. W., Schlegel, H. B., et al.: 2003, Gaussian 03, Revision B.03, Gaussian, Inc., Pittsburgh PA, 2003.

Giacopelli, P., Ford, K., Espada, C., and Shepson, P. B.: Comparison of the measured and simulated isoprene nitrate distributions above a forest canopy., J. Geophys. Res., 110, D01304,
doi:10.1029/2004JD005123, 2005.

Grosjean, E. and Grosjean, D.: The gas-phase reaction of alkenes with ozone: formation yields of carbonyls from biradicals in ozone-alkene-cyclohexane experiments. Atmos. Environ., 32, 3393-3402, 1998.

Grossenbacher, J. W., Barket, D. J., Shepson, P. B., et al.: A comparison of isoprene nitrate concentrations at two forest-impacted sites, J. Geophys. Res., 109, D11311, doi:10.1029/2003JD003966, 2004.

Guenther, A., Karl, T., Harley, P., Wiedinmyer, C., Palmer, P. I., and Geron, C.: Estimates of global terrestrial isoprene emissions using MEGAN (Model of Emissions of Gases and Aerosols from Nature), Atmos. Chem. Phys., 6, 3181-3210, doi:10.5194/acp-63181-2006, 2006.

Horowitz, L. W., Fiore, A. M., Milly, G. P., et al.: Observational constraints on the chemistry of isoprene nitrates over the eastern United States. J. Geophys. Res., 112, D12S08, doi:10.1029/2006JD007747, 2007.

Johnson, D., Rickard, A. R., McGill, C. D., et al.: The influence of orbital asymmetry on the kinetics of the gas-phase reactions of ozone with unsaturated compounds, Phys. Chem. Chem. Phys., 2 323-328, 2000.

Karl, M., Dorn, H. P., Hollandj, F., et al.: Product study of the reaction of $\mathrm{OH}$ radicals with isoprene in the atmosphere simulation chamber SAPHIR, J. Atmos. Chem., 55, 167-187 2006.

Kwok, E. S. and Atkinson, R.: Estimation of hydroxyl radical reaction rate constants for gas-phase organic compounds using a structure-reactivity relationship: an update, Atmos. Environ., 29, 1685-1695, 1995.

Lei, W., Zhang, R. Y., McGivern, W. S., et al.: Theoretical study of $\mathrm{OH}-\mathrm{O}_{2}$-isoprene peroxy radicals, J. Phys. Chem. A, 105, 471477, 2001.

Luxenhofer, O., Schneider, E., and Ballschmiter, K., et al.: Separation, detection and occurrence of $\left(\mathrm{C}_{2}-\mathrm{C}_{8}\right)$-alkyl- and phenylalkyl nitrates as trace compounds in clean and polluted air, Fresenius J. Anal. Chem., 350, 384-394, 1994.

Muthuramu, K., Shepson, P., and O'Brien, J. Preparation, analysis, and atmospheric production of multifunctional organic nitrates, Environ. Sci. Technol., 27, 1117-1124, 1993.

Nichols, P. L., Magnusson, A. B., and Ingham, J. D.: Synthesis of nitric esters by the addition of nitric acid o the ethylene oxide ring, J. Am. Chem. Soc., 75, 4255-4258, 1953.

Patchen, A. K., Pennino, M. J., Kiep, A. C., et al.: Direct kinetics study of the product-forming channels of the reaction of isoprene-derived hydroxyperoxy radicals with NO, Int. J. Chem. Kinet., 39, 353-361, 2007.

Paulot, F., Crounse, J. D., Kjaergaard, H. G., et al.: Unexpected Epoxide Formation in the Gas- Phase Photooxidation of Isoprene, Science, 325, 730-733, 2009a.

Paulot, F., Crounse, J. D., Kjaergaard, H. G., Kroll, J. H., Seinfeld, J. H., and Wennberg, P. O.: Isoprene photooxidation: new insights into the production of acids and organic nitrates, Atmos. Chem. Phys., 9, 1479-1501, doi:10.5194/acp-9-1479-2009, 2009b.

Perdew, J. P., Burke, K., and Wang, Y.: Generalized gradient approximation for the exchange-correlation hole of a manyelectron system, Phys. Rev. B., 54, 16533-16539, 1996.

Schneider, M., Luxenhofer, O., Deissler, A., et al.: $\mathrm{C}_{1}-\mathrm{C}_{15}$ alkyl nitrates, benzyl nitrate, and bifunctional nitrates: measurements 
in California and South Atlantic air and global comparison using $\mathrm{C}_{2} \mathrm{Cl}_{4}$ and $\mathrm{CHBr}_{3}$ as marker molecules, Environ. Sci. Technol., 32, 3055-3062, 1998.

Shepson, P. B., Mackay, E., and Muthuramu, K.: Henry's Law Constants and Removal Processes for Several Atmospheric $\beta$ Hydroxy Alkyl Nitrates, Environ. Sci. Technol., 30, 3618-3623, 1996.

Sprengnether, M., Demerjian, K. L., Donahue, N. M., et al.: Product analysis of the $\mathrm{OH}$ oxidation of isoprene and 1,3butadiene in the presence of NO, J. Geophys. Res., 107, 4269, doi:10.1029/2001JD000716, 2002.
Tuazon, E. C. and Atkinson, R.: A product study of the gas-phase reaction of isoprene with the $\mathrm{OH}$ radical in the presence of $\mathrm{NO}_{\mathrm{X}}$, Int. J. Chem. Kinet., 22, 1221-1236, 1990.

Wu, S. L., Mickley, L. J., Jacob, D. J., et al.: Why are there large differences between models in global budgets of tropospheric ozone?, J. Geophys. Res., 112, D05302, doi:10.1029/2006JD007801, 2007. 